\title{
Direct Blood Pressure Monitoring in Patients with Pheochromocytoma
}

\author{
Akikazu Nomura, M.D., Hisakazu Yasuda, M.D., \\ Kunihiko Kato, M.D., Hisashi Shimono, M.D., \\ Takeshi Murakami, M.D., Masaru Minami, M.D., \\ and Shigeru TAKechi, M.D.
}

\section{Summary}

In patients with pheochromocytoma, blood pressure was monitored continuously for 2 days using direct measurement techniques. Systolic blood pressure sometimes increased to more than $300 \mathrm{mmHg}$. These sudden elevations of blood pressure were associated with increased levels of plasma catecholamines. Preoperative prazosin and propranolol therapy lowered mean systolic and diastolic blood pressure throughout the 2 day observation periods and was associated with decreased hematocrit levels. However, these agents did not prevent the rapid elevation of blood pressure.

\section{Additional Indexing Words:}

Blood pressure monitoring Pheochromocytoma

\begin{abstract}
CONTINUOUS blood pressure monitoring has been used lately. ${ }^{1-3)}$ In $\checkmark$ the preoperative management of patients with pheochromocytoma, prazosin has been administered as an alpha-adrenoceptor blocking agent.4),5) In such patients we monitored the blood pressure changes, using continuous intra-brachial-arterial pressure measurements transmitted by telemetry, and the associated alterations of circulating catecholamines, collected through an indwelling venous catheter and measured by HPLC, 1) at control, 2) on prazosin and propranolol and 3) after surgery.
\end{abstract}

\section{Case Report}

Case 1: A 39 year old man was admitted to our hospital because of

\footnotetext{
From the Department of Cardiovascular Medicine, Hokkaido University, School of Medicine, Sapporo, Japan.

Address for reprint: Hisakazu Yasuda, M.D., Department of Cardiovascular Medicine, Hokkaido University, School of Medicine, Kita-15, Nishi-7, Sapporo 060, Japan.

Received for publication July 11, 1984.

Manuscript revised September 19, 1984.
} 


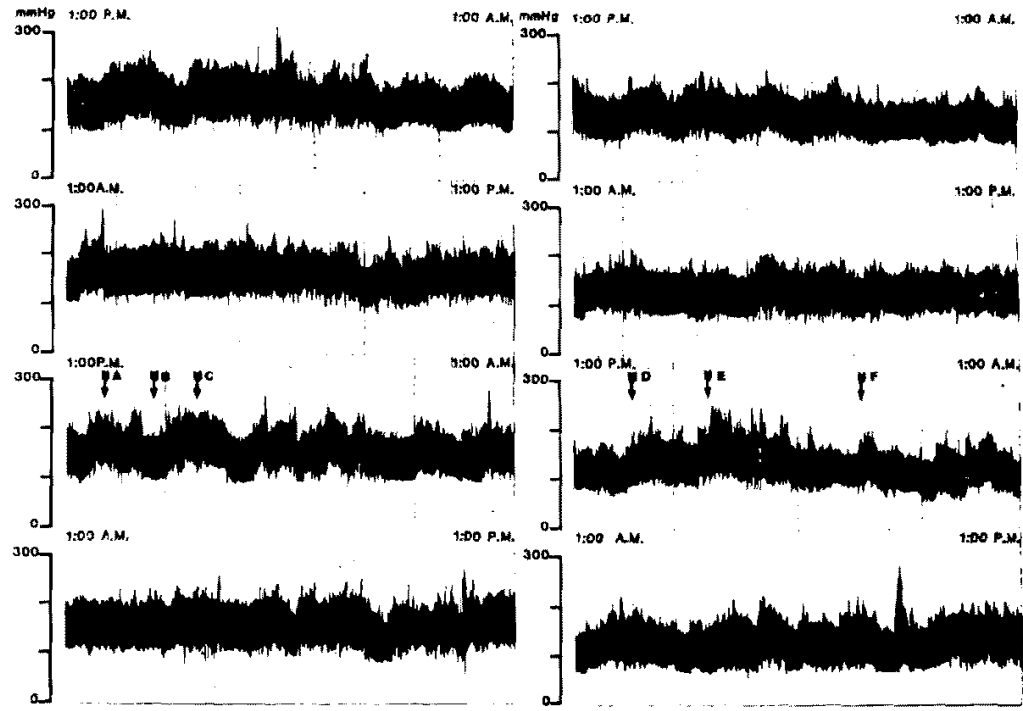

Fig. 1. Continuous recording of blood pressure over 2 days in Case 1. Left: at control. Right: on medical therapy. Arrow indicates the time of plasma catecholamine sampling. A: epinephrine $4241 \mathrm{pg} / \mathrm{ml}$, norepinephrine $1664 \mathrm{pg} / \mathrm{ml}$. B: 3825,1916 . C: 3256,1484 . D: 4662,1884 . E: 2852 , 1214. F: 3446,1424 , respectively.

Table I. Intra-arterial Blood Pressure

\begin{tabular}{|c|c|c|c|}
\hline \multirow{2}{*}{ Case No. } & \multicolumn{3}{|c|}{ Systolic pressure } \\
\hline & Control & Medical therapy & After operation \\
\hline 1 & $187 \pm 12(227-148)$ & $159 \pm 14(224-118)$ & $137 \pm 15(193-98)$ \\
\hline 2 & $170 \pm 18(263-135)$ & $155 \pm 29(261-119)$ & $110 \pm 14(170-74)$ \\
\hline 3 & $129 \pm 25 \quad(275-88)$ & $109 \pm 25(259-66)$ & $125 \pm 17 \quad(195-97)$ \\
\hline 4 & $122 \pm 37(321-66)$ & $108 \pm 23 \quad(245-73)$ & $111 \pm 14(165-75)$ \\
\hline \multirow{2}{*}{ Case No. } & \multicolumn{3}{|c|}{ Diastolic pressure } \\
\hline & Control & Medical therapy & After operation \\
\hline 1 & $117 \pm 9 \quad(143-86)$ & $92 \pm 9 \quad(126-65)$ & $84 \pm 11 \quad(117-52)$ \\
\hline 2 & $101 \pm 12(145-79)$ & $86 \pm 12(126-51)$ & $65 \pm 7 \quad(88-41)$ \\
\hline 3 & $69 \pm 9 \quad(116-46)$ & $62 \pm 11 \quad(115-35)$ & $77 \pm 10(115-58)$ \\
\hline 4 & $70 \pm 13(140-43)$ & $63 \pm 8 \quad(103-40)$ & $69 \pm 6 \quad(91-42)$ \\
\hline
\end{tabular}

Mean \pm SD (range): Mean blood pressure and standard deviation of the systolic and diastolic pressure for the 2 days were calculated by using 15-min pressures which were calculated every 15 $\min$ by averaging the $1-\mathrm{min}$ blood pressure. The blood pressure ranges are based on the 1 -min pressure measurement. 


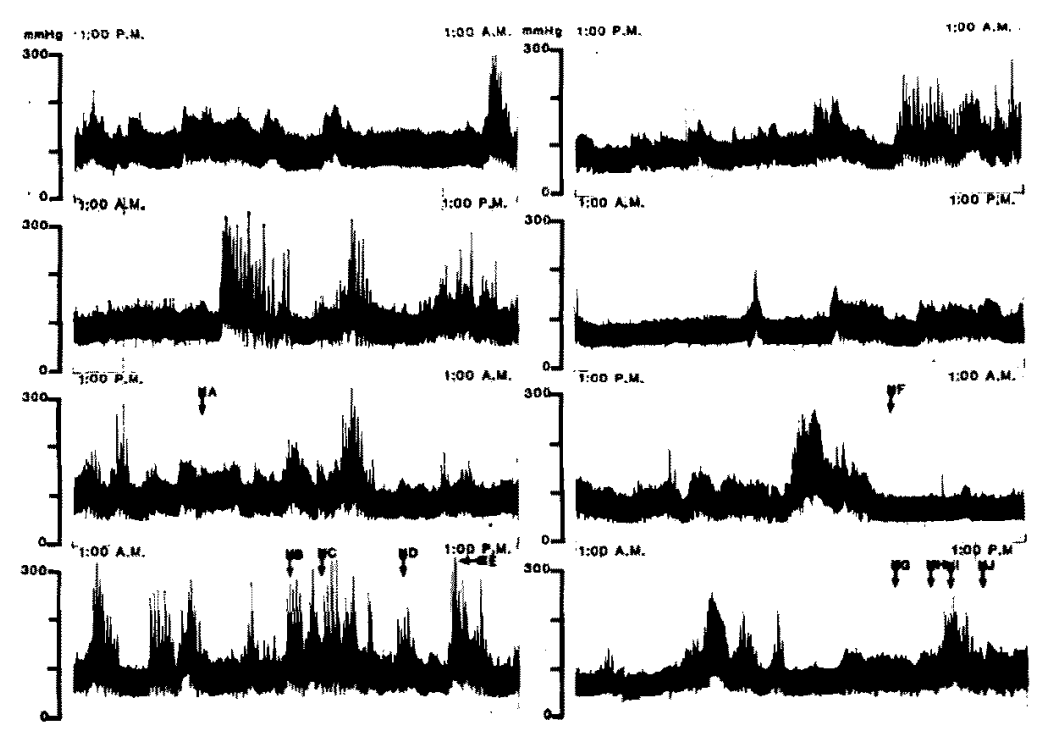

Fig. 2. Continuous recording of blood pressure over 2 days in Case 3 . Left: at control. Right: on medical therapy. Arrow indicates the time of plasma catecholamine sampling. A: epincphrine $2 / 2 \mathrm{pg} / \mathrm{ml}$, norepinephrine $2110 \mathrm{pg} / \mathrm{ml}$. B: 398,2640 . C: 170,1030 . D: $338,2140, \quad$ E: 850, 5620 . F : 148, 1380. G: 284, 2500. H: 418, 4280. I: 728, 7400. J: 198, 2510, respectively.

blurred vision. Findings on physical examination at the time of admission were within normal limits except for blood pressure $(190 / 130 \mathrm{mmHg}$ ) and papilledema of the optic fundi without neurological findings. Urine catecholamine levels were elevated: $338 \mu \mathrm{g} /$ day of epinephrine (EPI) (normal $<12 \mu \mathrm{g} /$ day) and $275 \mu \mathrm{g} /$ day of norepinephrine (NE) (normal 10-150 $\mu \mathrm{g} /$ day). Prazosin $17.5 \mathrm{mg}$ and propranolol $30 \mathrm{mg} /$ day were administered (Fig. 1). Hematocrit fell from $41.0 \%$ at control to $36.8 \%$ on medical therapy. A $188 \mathrm{Gm}$ pheochromocytoma in the left adrenal was removed. Recovery was uneventful. After operation, blood pressure returned to normal (130/ $90 \mathrm{mmHg}$ ) with plasma EPI $40 \mathrm{pg} / \mathrm{ml}$ (normal $<120 \mathrm{pg} / \mathrm{ml}$ ) and NE $188 \mathrm{pg} / \mathrm{ml}$ (normal $40-350 \mathrm{pg} / \mathrm{ml}$ ). Urinary excretion of catecholamines also decreased to normal levels ( $7 \mu \mathrm{g} /$ day of EPI and $133 \mu \mathrm{g} /$ day of NE) (Table I).

Case 2: A 33 year old woman was referred to our hospital because of headaches and palpitaions. Blood pressure of $180 / 120 \mathrm{mmHg}$ was the only abnormality detected on physical examination at admission. Her urine contained $738 \mu \mathrm{g} /$ day of EPI and $1540 \mu \mathrm{g} /$ day of NE. On prazosin $9 \mathrm{mg}$ and propranolol $40 \mathrm{mg} / \mathrm{day}$, blood pressure was $160 / 110 \mathrm{mmHg}$ with plasma EPI $2160 \mathrm{pg} / \mathrm{ml}$ and NE $8220 \mathrm{pg} / \mathrm{ml}$. Hematocrit fell $40.2 \%$ to $38.5 \%$. A $151 \mathrm{Gm}$ pheochromocytoma was removed from the left adrenal. Recovery 
was uneventful; postoperative blood pressure was normal $(120 / 78 \mathrm{mmHg})$. Plasma EPI and NE fell to $8 \mathrm{pg} / \mathrm{ml}$ and $210 \mathrm{pg} / \mathrm{ml}$ respectively. Urinary catecholamine excretion ( $3 \mu \mathrm{g} /$ day of EPI and $81 \mu \mathrm{g} /$ day of NE) was also normal (Table I).

Case 3: A 34 year old man was referred to our hospital for complaints of palpitations, headaches and chest pain. Findings on physical examination at admission were normal, including a blood pressure of $146 / 76 \mathrm{mmHg}$. Urine contained EPI $112 \mu \mathrm{g} /$ day and NE $383 \mu \mathrm{g} /$ day. Prazosin $22.5 \mathrm{mg}$ and propranolol $40 \mathrm{mg} /$ day were administered (Fig. 2). Hematocrit fell from $35.4 \%$ at control to $29.6 \%$ on medical therapy. A $45 \mathrm{Gm}$ pheochromocytoma in the right adrenal was removed. An uneventful recovery included a blood pressure $124 / 80 \mathrm{mmHg}$ with plasma EPI $16 \mathrm{pg} / \mathrm{ml}$ and NE $128 \mathrm{pg} / \mathrm{ml}$. Urinary EPI of $4 \mu \mathrm{g} /$ day and NE of $89 \mu \mathrm{g} /$ day were also normal (Table I).

Case 4: A 50 year old man was referred to our hospital for complaints of palpitations, pallor, and nausea. Findings on physical examination at admission were normal, including a blood pressure $110 / 66 \mathrm{mmHg}$. Urine contained EPI $380 \mu \mathrm{g} /$ day and NE $565 \mu \mathrm{g} /$ day. At control, the plasma EPI of $1091 \mathrm{pg} / \mathrm{ml}$ and $\mathrm{NE}$ of $2470 \mathrm{pg} / \mathrm{ml}$ corresponded with a blood pressure $122 / 82 \mathrm{mmHg}$; these increased to $5000 \mathrm{pg} / \mathrm{ml}$ and $7540 \mathrm{pg} / \mathrm{ml}$ respectively, with a corresponding increase of blood pressure to $287 / 117 \mathrm{mmHg}$. Plasma EPI, $934 \mathrm{pg} / \mathrm{ml}$, and $\mathrm{NE}, 2230 \mathrm{pg} / \mathrm{ml}$, rose to $5430 \mathrm{pg} / \mathrm{ml}$ and $9150 \mathrm{pg} / \mathrm{ml}$ respectively during treatment with prazosin $16 \mathrm{mg}$ and propranolol $40 \mathrm{mg} / \mathrm{day}$ when blood pressure increased from $96 / 57 \mathrm{mmHg}$ to $204 / 94 \mathrm{mmHg}$. Hematocrit decreased from $42.2 \%$ to $36.1 \%$. A $68 \mathrm{Gm}$ pheochromocytoma of the left adrenal was removed. Recovery was uneventful. Postoperative blood pressure was $108 / 70 \mathrm{mmHg}$. Plasma EPI, $24 \mathrm{pg} / \mathrm{ml}$, and NE, $66 \mathrm{pg} / \mathrm{ml}$, were normal as was urinary catecholamine excretion (EPI, $5 \mu \mathrm{g} /$ day and NE, $74 \mu \mathrm{g} /$ day) (Table I).

\section{Discussion}

The patients who experienced sudden elevations of blood pressure had associated increases in plasma catecholamine concentrations as has been reported previously. ${ }^{6)}$ Prazosin lowered mean systolic and diastolic pressure throughout the 2 days. Various alpha-adrenoceptor blocking agents have been used preoperatively to control blood pressure.4),51,7),3) Alpha-adrenoceptor blocking agents can be classified into two general categories: competitive inhibitors (e.g. phentolamine and prazosin) and noncompetitive inhibitors (e.g. phenoxybenzamine). The competitive inhibitor simply moves the dose-related response curve for the agonist to the right without altering 
the slope or the maximum response. ${ }^{91}$ In our study, prazosin appeared to act as a competitive inhibitor and lowered mean systolic and diastolic blood pressure during therapy. However, this antagonist could not prevent the rapid elevation of blood pressure due to the massive surge in agonist which presumably could override the inhibition. In addition, EPI and NE have equal affinity for both alpha $_{1}$ - and alpha ${ }_{2}$-adrenoceptors and prazosin is a selective alpha ${ }_{1}$-adrenoceptor blocking agent. ${ }^{101}$ Vasoconstriction is produced not only by postsynaptic alpha ${ }_{1}$-adrenoceptors but also by postsynaptic alpha $\mathrm{a}_{2^{-}}$ adrenoceptors. ${ }^{10), 11)}$ The sudden elevation of blood pressure in the presence of prazosin could be due, in part, to postsynaptic alpha ${ }_{2}$-adrenoceptor activation. These phenomena may explain why prazosin did not prevent the rapid blood pressure fluctuation.

Prazosin also lowered the hematocrit. Phentolamine and phenoxybenzamine are reported to reduce hematocrit and thereby restore plasma volume. ${ }^{12)}$ Lowered hematocrit was thought to be beneficial in short term preoperative therapy with prazosin and propranolol. However, we found this drug combination to be ineffective in preventing the rapid elevation of blood pressure in these patients.

\section{ACKNOWLedgment}

We would like to thank Maris Mason for her help in preparation of the manuscript.

\section{REFERENCES}

1. Littler WA, Honour AJ: Direct arterial pressure, heart rate, and electrocardiogram in unrestricted patients before and after removal of a pheochromocytoma. Quart J Med 63: 441,1974

2. Horan MJ, Padgett NE, Kennedy HL: Ambulatory blood pressure monitoring. Recent advances and clinical applications. Am Heart J 101: 843, 1981

3. Gould BA, Mann S, Kieso H, Subramanian VB, Raftery EB: The 24-hour ambulatory blood pressure profile with verapamil. Circulation 65: 22, 1982

4. Wallace JM, Gill DP: Prazosin in the diagnosis and treatment of pheochromocytoma. JAMA 240: 2752, 1978

5. Cubeddu LX, Zarate NA, Rosales CB, Zscaeck DW: Prazosin and propranolol in preoperative management of pheochromocytoma. Clin Pharmacol Ther 32: 156, 1982

6. Messerli FH, Finn M, MacPhee AA: Pheochromocytoma of the urinary bladder. JAMA 247: 1863,1982

7. Ross EJ, Prichard BNC, Kaufman L, Robertson AIG, Harries BJ: Preoperative and operative management of patients with pheochromocytoma. Br Mcd J 1: 191, 1967

8. Sjoerdsma A, Engelman K, Waldman TA, Cooperman LH, Hammond WG: Pheochromocytoma. Current concepts of diagnosis and treatment. Ann Int Med 65: 1302, 1966

9. Goldstein A, Aronow L, Kalman SM: Principles of Drug Action. Wiley, New York, p 82, 1974

10. Langer SZ: Presynaptic regulation of the release of catecholamines. Pharm Rev 32: 337 , 
1980

11. Langer SZ, Shepperson NB: Recent development in vascular smooth muscle pharmacology: the post-synaptic alpha ${ }_{2}$-adrenoceptor. Trends Pharmacol Sci 3: 440, 1982

12. Johns VJ, Brunjes S: Pheochromocytoma. Am J Cardiol 9: 120, 1962 